\title{
Endocrine disruptors and prostate cancer risk
}

\author{
Gail S Prins \\ Department of Urology, University of Illinois at Chicago, 820 South Wood St, MC 955, Chicago, \\ Illinois 60612, USA
}

\begin{abstract}
There is increasing evidence both from epidemiology studies and animal models that specific endocrine-disrupting compounds may influence the development or progression of prostate cancer. In large part, these effects appear to be linked to interference with estrogen signaling, either through interacting with ERs or by influencing steroid metabolism and altering estrogen levels within the body. In humans, epidemiologic evidence links specific pesticides, PCBs and inorganic arsenic exposures to elevated prostate cancer risk. Studies in animal models also show augmentation of prostate carcinogenesis with several other environmental estrogenic compounds including cadmium, UV filters and BPA. Importantly, there appears to be heightened sensitivity of the prostate to these endocrine disruptors during the critical developmental windows including in utero and neonatal time points as well as during puberty. Thus infants and children may be considered a highly susceptible population for ED exposures and increased risk of prostate cancers with aging.
\end{abstract}

\section{Introduction}

Prostate cancer is the most common solid cancer in males and is the second leading cause of cancer deaths in American men (Jemal et al. 2008). While rates today are markedly higher than rates observed three decades ago, the most recent statistics show that prostate cancer incidence rates have now stabilized which is thought to reflect changes in utilization of prostate-specific antigen (PSA) testing. In addition, benign prostatic hyperplasia (BPH) is the most common benign neoplasm, occurring in $\sim 50 \%$ of all men by the age of 60 . Despite extensive research, the basis for these high rates of abnormal prostatic growth is not well understood. It is recognized, however, that steroids play a role in the initiation and progression of prostate cancer which is the basis for hormonal treatment strategies. Eunuchs do not develop prostatic carcinoma (Moore 1947) and regression of the cancer can be initially achieved by castration and androgen blockade (Huggins \& Hodges 1941). In addition to androgens, estrogen involvement in the etiology of BPH and prostatic cancer has been postulated and the use of anti-estrogens has been recently recognized to have a therapeutic role in prostate cancer management (Prins \& Korach 2008, Raghow et al. 2002, Steiner \& Pound 2003, Smith et al. 2008). Human and rodent prostates express both estrogen receptor $\alpha(\mathrm{ER} \alpha)$ and ER $\beta$ during development and into adulthood with ER $\alpha$ primarily found in stromal cells (Schulze \& Claus 1990, Prins \& Birch 1997) and ER $\beta$ in differentiated epithelium (Enmark et al. 1997, Prins et al. 1998). Furthermore, it is believed that early prostatic developmental events which are regulated by steroids may be linked to the predisposition of this structure to high rates of disease in adult men (Henderson et al. 1988, 1991). It is noteworthy that relative to adult estrogenic

C) 2008 Society for Endocrinology

Correspondence should be addressed to G S Prins; gprins@uic.edu.

Declaration of interest

The authors declare that there is no conflict of interest that would prejudice the impartiality of this scientific work. 
responses, the prostate gland is particularly sensitive to estrogen exposures during the critical developmental period (Prins et al. 2007).

The established risk factors for prostate cancer are age and race with African American men possessing the highest incidence of prostate cancer worldwide, at rates twofold of those for Caucasian-American counterparts. It is also recognized that genetics (family history), diet, and environmental factors can impact prostate cancer risk. In the human population, direct connections between endocrine disruptors (EDs) and prostate cancer risk have not been established. Nonetheless, due to the hormonal basis of this disease and the evidence that dietary compounds high in isoflavones (e.g., red clover, genistein) can control prostate cancer growth in humans (Jarred et al. 2002, Lakshman et al. 2008) and animal models (McCormick et al. 2007), there is reasonable cause to evaluate and understand any potential relationship between environmental EDs and prostate cancer risk. In addition to epidemiologic studies, there are in vitro studies with human prostate cells and in vivo studies in animal models that indicate associations between EDs and prostate cancer, carcinogenesis, and/or susceptibility. Due to difficulties in directly associating prostate cancer risk in humans with ED exposures, potential risk(s) will have to include research with animal models, particularly those that that are responsive to environmentally relevant exposures.

\section{Evidence and mechanisms}

\section{Farming and pesticides}

Regarding links between prostate cancer and environmental factors in humans (outside of diet), the most compelling data come from the established occupational hazard of farming and increased prostate cancer rates (Morrison et al. 1993, Alavanja et al. 2003, Meyer et al. 2007). While several variables may contribute to higher prostate cancer rates in farmers, chronic or intermittent exposures to pesticides are the most likely explanation (Alavanja $e t$ al. 2003, Van Maele-Fabry et al. 2006). This is supported by a large epidemiology study (Agricultural Health Study) in a collaborative effort between the NCI, NIEHS, and EPA in the United States that has examined agricultural lifestyles and health in $~ 90000$ participants in North Carolina and Iowa since 1993 (www.aghealth.org). Evaluation of $>55000$ pesticide applicators revealed a direct link between methyl bromide exposure, a fungicide with unknown mode of action, and increased prostate cancer rates. Furthermore, 6 pesticides out of 45 common agricultural pesticides showed correlation with exposure and increased prostate cancer in men with a familial history, suggesting gene-environment interactions. These six agents were chlorpyrifos, fonofos, coumaphos, phorate, permethrin, and butylate (Alavanja et al. 2003, Mahajan et al. 2006). The first four of these compounds are thiophosphates and share a common chemical structure. While these agents are regarded as acetylcholine esterase inhibitors and have not been shown to have direct estrogenic or anti-androgenic activities, a literature search revealed that these compounds have significant capacity as p450 enzyme inhibitors. In particular, chlorpyrifos, fonofos, and phorate strongly inhibit CYP1A2 and CYP3A4 which are the major p450s that metabolize estradiol, estrone, and testosterone in the liver (Usmani et al. 2003, 2006). Furthermore, the human prostate constitutively expresses CYP1A2 and CYP3A4 enzymes that are involved in intraprostatic metabolism of steroids, drugs, and dietary compounds (Finnström et al. 2001, Lawson \& Kolar 2002, Sterling \& Cutrineo 2004). This raises the possibility that exposure to these compounds may interfere with steroid hormone metabolism by the liver as well as the prostate and, in so doing, alter steroid balance and availability which in turn may contribute to increased prostate cancer risk. A similar mechanism of endocrine disruption in vivo has been identified for polychlorinated biphenols (PCBs) and polyhalogenated aromatic hydrocarbons (including dioxins, bisphenol A (BPA), and dibenzofurans) through potent inhibition of estrogen sulfotransferase which effectively elevates bioavailable estrogens in various target organs (Kester et al. 2000, 2002). 


\section{Environmental estrogens}

In men, chronically elevated estrogens have been associated with increased risk of prostate cancer (Modugno et al. 2001). In rodents, estrogens in combination with androgens induce prostate cancer (Leav et al. 1988). For the sake of simplicity, we here refer to environmental estrogens as molecules with identified estrogenic activity (estrogen mimics), mostly through activation of ERs.

Diethylstilbestrol (DES)—DES exposure is considered an important model of endocrine disruption and provides proof of principle for exogenous estrogenic agents as disruptors of multiple endorgans. Maternal exposure to DES during pregnancy was found to result in more extensive prostatic squamous metaplasia in human male offspring than observed with maternal estradiol alone (Driscoll \& Taylor 1980). While prostatic metaplasia eventually resolved following DES withdrawal, ectasia and persistent distortion of ductal architecture remained (Yonemura et al. 1995). This has lead to the postulation that men exposed prenatally to DES may be at increased risk for prostatic disease later in life although this has not been borne out in the limited population studies conducted to date (Giusti et al. 1995). However, extensive studies with DES in rodent models predict marked abnormalities in the adult prostate including increased susceptibility to adult-onset carcinogenesis following early DES exposures (Rajfer \& Coffey 1978, Arai et al. 1983, Prins et al. 2001, Huang et al. 2004).

BPA-BPA is a synthetic polymer used in the production of polycarbonate plastics and expoxy resins and significant levels have been found in the urine of $93 \%$ of US population in a recent screen by the CDC (Calafat et al. 2008). The relative binding affinity of BPA for either ER $\alpha$ and ER $\beta$ or capacity for BPA to activate ER-dependent transcription is $\sim 10000$ lower than estradiol or diethylstilbestrol (Kuiper et al. 1998, Lemmen et al. 2004). While these data might suggest that BPA has minimal estrogenic activity, $1 \mu \mathrm{M}$ BPA is $50 \%$ as efficacious as $1 \mu \mathrm{M}$ $17 \beta$-estradiol in activating an estrogen-responsive luciferase reporter (Kurosawa et al. 2002). This indicates that, although BPA may have a significantly lower potency than endogenous estrogens in vitro, it is a full agonist for both ER $\alpha$ and ER $\beta$. Furthermore, BPA induces ER through non-genomic pathways with an $\mathrm{EC}_{50}$ equivalent to $17 \beta$ estradiol suggesting that in vivo estrogenic activity of BPA may be due to non-genomic activation of ER (Song et al. 2002, Walsh et al. 2005).

The effects of BPA with regard to carcinogenic potential, including the prostate gland, have recently been reviewed by an expert panel (Keri et al. 2007). In short, there is evidence from rodent models and human prostate cell lines that BPA can influence carcinogenesis, modulate prostate cancer cell proliferation, and for some tumors, stimulate progression. The recent reports have provided evidence that early life exposure to BPA may increase susceptibility to hormonal carcinogenesis in the prostate gland, possibly by developmentally reprogramming carcinogenic risk (Ho et al. 2006, Prins et al. 2008). Studies using a rat model showed that brief neonatal exposure to a low dose of BPA (10 $\mu \mathrm{g} / \mathrm{kg}$ BW/day) significantly increased the incidence and grade of prostatic intraepithelial neoplasia following adult estrogen exposure. This model of sensitivity to hormonal carcinogenesis is relevant to humans in that relative estradiol levels increase in the aging male and may contribute to prostate disease risk (Kaufman \& Vermeulen 2005). The above studies further identified alterations in DNA methylation patterns in multiple cell signaling genes in BPA-exposed prostates which suggest that environmentally relevant doses of BPA 'imprint' the developing prostate through epigenetic alterations (Ho et al. 2006, Prins et al. 2008).

Knudsen et al. examined the influence of BPA on human prostate cancer cells that contained an androgen receptor (AR) point mutation (AR-T877A) frequently found in advanced prostate cancers of patients who relapsed after androgen deprivation therapy (Wetherill et al. 2005). 
They first observed that $1 \mathrm{nM}$ BPA activates AR-T877A in transcriptional assays and leads to unscheduled cell cycle progression and cellular proliferation in vitro in the absence of androgen. Since BPA had no impact on wild-type AR, these data indicate that this gain-offunction AR mutant attained the ability to utilize BPA as an agonist. Subsequent in vivo analyses of the impact of BPA on human prostate tumor growth and recurrence were performed using a mouse xenograft of human cells containing the AR-T877A mutation (Wetherill et al. 2006). At low doses that fall within the reported ranges of human exposure, prostate tumor size increased in response to BPA administration when compared with placebo control and mice in the BPA cohort demonstrated an earlier rise in PSA (biochemical failure). These findings indicating that BPA significantly shortened the time to therapeutic relapse. These outcomes underscore the need for further study of the effects of BPA on tumor progression and therapeutic efficacy.

PCBs-Persistent organic pollutants, such as PCBs, are fat soluble chemicals that bioaccumulate in the human body. Many have estrogenic or anti-androgenic activity and as such, may perturb male reproductive activity. A recent analysis of adipose tissue concentrations of PCBs in Swedish men with and without prostate cancer revealed a significant association between PCB levels in the higher quandrants and prostate cancer odds ratio with the most marked associations for PCB 153 and trans-chlordane (Hardell et al. 2006). A more extensive epidemiologic study of capacitor manufacturing plant workers highly exposed to PCBs revealed a strong exposure-response relationship for prostate cancer mortality (Prince $e t$ al. 2006). This supports previous findings of correlations between PCB 153 and 180 and prostate cancer risk in electric utility workers (Charles et al. 2003, Ritchie et al. 2003). While estrogenic activity of these compounds is a suspected mode of action, there is also evidence that PCBs inhibit estrogen sulfotransferase activity in the liver and effectively increase bioavailable estrogen in the body (Kester et al. 2000). Recently, Aroclor-1254, a mixture of 60 PCB pollutants, was tested on rat prostate cells in vitro and shown to disrupt gap junctions, expression of connexin 32 and 43 and increase double-stranded DNA breaks suggesting that PCBs may be able to transform prostate cells leading to carcinogenesis (Cillo et al. 2007). Further investigation using animal models is warranted for PCBs and prostate cancer risk.

Ultraviolet (UV) filters-There are a few recent reports that UV light filters that are used to protect against the sun have estrogenic activity (Schlumpf et al. 2004b). Specifically, 4methylbenzylidene camphor and 3-benzylidene camphor (3-BC) are ER $\beta$ ligands (Schlumpf et al. 2004a). While little if any work has been done with regard to these UV filters and human prostate cancer, a few recent reports indicate that developmental exposure to the compounds can alter prostate gland development and estrogen target gene expression in the rat (Schlumpf et al. 2004b, Hofkamp et al. 2008). This raises the possibility that the fetal prostate may be affected following maternal use of these compounds.

Cadmium-Cadmium is known to ligand to ERs and function as an estrogenic mimic. While some large epidemiologic reports have indicated a relationship between cadmium exposure and prostate cancer rates, others have refuted these findings (Parent \& Siemiatycki 2001). Nonetheless, there are intriguing reports in the literature which show that cadmium has proliferative action with human prostate cells in vitro through an ER-dependent mechanism and that this exposure is associated with acquisition of androgen independence (BenbrahimTallaa et al. 2007b). Furthermore, prostatic tumors have been shown to be experimentally induced by oral exposure to cadmium (Waalkes 2000). Since cadmium bioaccumulates in the body, further epidemiologic analysis of cadmium and prostate cancer risk is warranted, particularly in men with occupational exposures. 
Arsenic-Exposure to arsenic has long been associated with a number of diseases including cancers (Chen et al. 1988, Watson \& Yager 2007). A recent review of the epidemiologic data has shown an association between inorganic arsenic exposure from the environment and prostate cancer incidence and mortality in the human population (Benbrahim-Tallaa \& Waalkes 2008). Importantly, it has been documented that arsenic may mediate some of these effects through endocrine disruption, specifically through interaction with ERs and activation of estrogen-regulated genes (Davey et al. 2007). In this context, there is a recent report that arsenic can induce malignant transformation of prostate epithelial cells in vitro and drive them toward an androgen-independent state (Benbrahim-Tallaa et al. 2007a). Interestingly, this was shown to be mediated through Ras-MAPK pathways and it is possible that membrane ERs may be involved in this process. Epidemiologic studies have shown an association between arsenic exposure and prostate cancer mortality in Taiwan (Chen et al. 1988), a finding that was substantiated by a later study in the United States (Lewis et al. 1999). Thus, it is possible that endocrine disruption by arsenic can contribute to prostate cancer risk.

\section{Anti-androgens}

While there are no known environmental androgens, EDs can also function through antiandrogenic pathways. Since prostate cancer is an androgen-dependent disease, we will briefly examine the known effects of some of these agents on the prostate gland.

Vinclozolin-Vinclozolin is a fungicide that is used as a pesticide on crops. It has known anti-androgenic properties by interfering with AR activity (Kavlok \& Cummings 2005). Since vinclozolin effects are driven through AR antagonism, it is not surprising that there are no reported associations between this compound and prostate cancer, an androgen-dependent disease. Exposure of rats to vinclozolin during development results in reduced prostate gland growth and size which would be expected for an anti-androgen (Yu et al. 2004). Of interest, however, are recent studies with maternal (i.e. in utero) exposure to vinclozolin in rats which produce transgenerational effects on offspring through epigenetic alterations (Anway et al. 2005). These permanent perturbations include adverse consequences on the prostate gland such as premature acinar atrophy and aging-associated prostatitis for four generations (Anway \& Skinner 2008). This may be particularly significant in light of recent evidence that chronic inflammation may play a role in prostate cancer initiation (Nelson et al. 2002).

\section{Dichlorodiphenyltrichloroethane/dichlorodiphenyl-dichloroethylene (DDT/} DDE) -DDT and its metabolic derivative p,p'-DDE were widely used as pesticides in the United States and their use is still in effect in other countries worldwide. In addition to AR antagonistic effects (Gray et al. 1999), p,p'-DDE at high concentrations has been shown to function as an inhibitor of $5 \alpha$-reductase, the intrapro-static enzyme responsible for converting testosterone to the more potent androgen, dihydrotestosterone (Lo et al. 2007). While many reproductive abnormalities have been found with DDT/DDE exposure, including reduced prostate growth, there is no known association between exposure to DDT/p,p'-DDE and prostate cancer risk.

\section{Summary and key questions}

There is increasing evidence both from epidemiology studies and animal models that specific endocrine-disrupting compounds may influence the development or progression of prostate cancer. In large part, these effects appear to be linked to interference with estrogen signaling, either through interacting with ERs or by influencing steroid metabolism and altering estrogen levels within the body. In humans, epidemiologic evidence links specific pesticides, PCBs, and inorganic arsenic exposures to elevated prostate cancer risk. Studies in animal models also show augmentation of prostate carcinogenesis with several other environmental estrogenic 
compounds including cadmium, UV filters, and BPA. Importantly, there appears to be heightened sensitivity of the prostate to these EDs during the critical developmental windows including in utero and neonatal time points as well as during puberty. Thus, infants and children may be considered a highly susceptible population for ED exposures and increased risk of prostate cancers with aging.

There are several key questions that must be addressed in the future studies in order to best appreciate and understand the risks of prostate disease as they relate to endocrine-disrupting chemicals.

1. What specific ED chemicals can influence the prostate gland and increase prostate cancer risk or progression?

2. What are their modes of action?

3. Are there epigenetic pathways that mediate developmental exposures to EDs and prostate disease with aging?

4. Is there an additive or synergistic effect from ED mixtures and prostate cancer risk or growth?

5. Does ED exposure influence prostate cancer susceptibility in subpopulations of men? Are there specific pathways with which ED chemicals synergize to influence prostate cancer incidence and/or progression?

6. Is the in utero developing human prostate sensitive to ED chemicals and do they influence prostate cancer risk in the aging male? What are the most appropriate life stages for examining ED and prostate cancer risk?

7. Is there a transgenerational risk for prostate cancer as a function of ED exposures?

8. Can we establish molecular markers for ED exposures as they relate to prostate disease risk?

Focused research on these and other specific questions is required in order to adequately evaluate the human risk for prostate disease from the growing accumulation of EDs in the environment. Insight into molecular mechanisms may help to provide biomarkers for prostate disease risk from ED exposure as well as to provide opportunities for therapeutic intervention.

\title{
Acknowledgments
}

\author{
Funding \\ Funded in part by a grant from the National Institutes of Health, R01 ES015584.
}

\section{References}

Alavanja MC, Samanic C, Dosemeci M, Lubin J, Tarone R, Lynch CF, Knott C, Thomas K, Hoppin JA, Barker J, et al. Use of agricultural pesticides and prostate cancer risk in the Agricultural Health Study cohort. American Journal of Epidemiology 2003;157:800-814. [PubMed: 12727674]

Anway M, Skinner M. Transgenerational effects of the endocrine disruptor vinclozolin on the prostate transcriptome and adult onset disease. Prostate 2008;68:515-529.

Anway MD, Cupp AS, Uzumcu M, Skinner MK. Epigenetic transgenerational actions of endocrine disuptors and male fertility. Science 2005;308:1466-1469. [PubMed: 15933200]

Arai, Y.; Mori, T.; Suzuki, Y.; Bern, HA. Long-term effects of perinatal exposure to sex steroids and diethylstilbestrol on the reproductive system of male mammals. In: Bourne, GHADJF., editor. International Review of Cytology. New York: Academic Press, Inc.; 1983. p. 235-268. 
Benbrahim-Tallaa L, Waalkes MP. Inorganic arsenic and human prostate cancer. Environmental Health Perspectives 2008;116:158-164. [PubMed: 18288312]

Benbrahim-Tallaa L, Webber MM, Waalkes MP. Mechanisms of acquired androgen independence during arsenic-induced malignant transformation of human prostate epithelial cells. Environmental Health Perspectives 2007a;115:243-247. [PubMed: 17384772]

Benbrahim-Tallaa L, Liu J, Webber MM, Waalkes MP. Estrogen signaling and disruption of androgen metabolism in acquired androgen-independence during cadmium carcinogenesis in human prostate epithelial cells. Prostate 2007b;67:135-145. [PubMed: 17075824]

Calafat AM, Ye X, Wong LY, Reidy JA, Needham LL. Exposure of the US population to bisphenol A and 4-tertiary-octylphenol: 2003-2004. Environmental Health Perspectives 2008;116:39-44. [PubMed: 18197297]

Charles LE, Loomis D, Shy CM, Newman B, Millikan R, Nylander-French LA, Couper D. Electromagnetic fields, polychlorinated biphenyls, and prostate cancer mortality in electric utility workers. American Journal of Epidemiology 2003;157:683-691. [PubMed: 12697572]

Chen CJ, Kuo T, Wu M. Aresenic and cancers. Lancet 1988;1:414-415. [PubMed: 2893213]

Cillo F, de Eguileor M, Gandolfi F, Brevini T. Aroclor-1254 affects mRNA polyadenylation, translational activation, cell morphology, and DNA integrity of rat primary prostate cells. Endocrine-Related Cancer 2007;14:257-266. [PubMed: 17639042]

Davey JC, Bodwell JE, Gosse JA, Hamilton J. Arsenic as an endocrine disruptor: effects of arsenic on estrogen receptor-mediated gene expression in vivo and in cell culture. Toxicological Sciences 2007;98:75-86. [PubMed: 17283378]

Driscoll SG, Taylor SH. Effects of prenatal maternal estrogen on the male urogenital system. Obstetrics and Gynecology 1980;56:537-542. [PubMed: 7432722]

Enmark E, Pelto-Huikko M, Grandien K, Lagercrantz S, Lagercrantz J, Fried G, Nordenskjold M, Gustafsson J. Human estrogen receptor $\beta$-gene structure, chromosomal localization, and expression pattern. Journal of Clinical Endocrinology and Metabolism 1997;82:4258-4265. [PubMed: 9398750]

Finnström N, Bjelfman C, Söderström T, Smith G, Egevad L, Norlén B, Wolf CR, Rane A. Detection of cytochrome P450 mRNA transcripts in prostate samples by RT-PCR. European Journal of Clinical Investigation 2001;31:880-886. [PubMed: 11737226]

Giusti RM, Iwamoto K, Hatch EE. Diethylstilbestrol revisited: a review of the long-term health effects. Annals of Internal Medicine 1995;122:778-788. [PubMed: 7717601]

Gray LE, Wolf C, Lambright C, Mann P, Price M, Cooper RL, Ostby J. Administration of potentially antiandrogenic pesticides (procymidone, linuron, iprodione, chlozolinate, p,p'-DDE, and ketoconazole) and toxic substances (dibutyl- and diethylhexyl phthalate, PCB 169, and ethane dimethane sulphonate) during sexual differentiation produces diverse profiles of reproductive malformations in the male rat. Toxicology and Industrial Health 1999;15:94-118. [PubMed: 10188194]

Hardell L, Andersson SO, Carlberg M, Bohr L, van Bavel B, Lindström G, Björnfoth H, Ginman C. Adipose tissue concentrations of persistent organic pollutants and the risk of prostate cancer. Journal of Occupational and Environmental Medicine 2006;48:700-707. [PubMed: 16832227]

Henderson BE, Bernstein L, Ross RK, Depue RH, Judd HL. The early in utero oestrogen and testosterone environment of blacks and whites: potential effects on male offspring. British Journal of Cancer 1988;57:216-218. [PubMed: 3358915]

Henderson BE, Ross RK, Pike MC. Toward the primary prevention of cancer. Science 1991;254:11311136. [PubMed: 1957166]

Ho SM, Tang WY, Belmonte J, Prins GS. Developmental exposure estradiol and bisphenol A (BPA) increases susceptibility to prostate carcinogenesis and epigenetically regulates phosphodisesterase type 4 variant (PDE4D4) in the rat prostate. Cancer Research 2006;66:5624-5632. [PubMed: 16740699]

Hofkamp L, Bradley S, Tresguerres J, Lichtensteiger W, Schumpf M, Timms B. Region-specific growth effects in the developing rat prostate following developmental exposure to estrogenic UV filters. Environmental Health Perspectives. 2008 in press. 
Huang L, Pu Y, Alam S, Birch L, Prins GS. Estrogenic regulation of signaling pathways and homeobox genes during rat prostate development. Journal of Andrology 2004;25:330-337. [PubMed: 15064308]

Huggins C, Hodges CF. Studies on prostatic cancer. I. The effect of castration, of estrogen, and of androgen injection on serum phosphatases in metastic carcinoma of the prostate. Cancer Research 1941;1:293-297.

Jarred RA, Keikha M, Dowling C, McPherson SJ, Clare AM, Husband AJ, Pedersen JS, Frydenberg M, Risbridger GP. Induction of apoptosis in low to moderate-grade human prostate carcinoma by red clover-derived dietary isoflavones. Cancer Epidemiology, Biomarkers and Prevention 2002;11:1689-1696.

Jemal A, Siegel R, Ward E, Hao Y, Xu J, Murray T, Thun MJ. Cancer Statistics, 2008. CA: A Cancer Journal for Clinicians 2008;58:71-96. [PubMed: 18287387]

Kaufman JM, Vermeulen A. The decline of androgen levels in elderly men and its clinical and therapeutic implications. Endocrine Reviews 2005;26:833-876. [PubMed: 15901667]

Kavlok R, Cummings A. Mode of action: inhibition of androgen receptor function - vinclozolin-induced malformations in reproductive development. Critical Reviews in Toxicology 2005;35:721-726. [PubMed: 16417039]

Keri R, Ho SM, Hunt PA, Knudsen KE, Soto AM, Prins GS. An evaluation of evidence for the carcinogenic activity of bisphenol A: report of NIEHS Expert Panel on BPA. Reproductive Toxicology 2007;24:240-252. [PubMed: 17706921]

Kester MH, Bulduk S, Tibboel D, Meinl W, Glatt H, Falany CN, Coughtrie MW, Bergman A, Safe SH, Kuiper GG, et al. Potent inhibition of estrogen sulfotransferase by hydroxylated PCB metabolites: a novel pathway explaining the estrogenic activity of PCBs. Endocrinology 2000;141:1897-1900. [PubMed: 10803601]

Kester MH, Bulduk S, van Toor H, Tibboel D, Meinl W, Glatt H, Falany CN, Coughtrie MW, Schuur AG, Brouwer A, et al. Potent inhibition of estrogen sulfotransferase by hydroxylated metabolites of polyhalogenated aromatic hydrocarbons reveals alternative mechanism for estrogenic activity of endocrine disrupters. Journal of Clinical Endocrinology and Metabolism 2002;87:1142-1150. [PubMed: 11889178]

Kuiper GG, Lemmen JG, Carlsson B, Corton JC, Safe SH, van der Saag PT, van der Burg B, Gustafsson JA. Interaction of estrogenic chemicals and phytoestrogens with estrogen receptor beta. Endocrinology 1998;139:4252-4263. [PubMed: 9751507]

Kurosawa T, Hiroi H, Tsutsumi O, Ishikawa T, Osuga Y, Fujiwara T, Inoue S, Muramatsu M, Momoeda M, Taketani Y. The activity of bisphenol A depends on both the estrogen receptor subtype and the cell type. Endocrine Journal 2002;49:465-471. [PubMed: 12402979]

Lakshman M, Xu L, Ananthanarayanan V, Cooper J, Takimoto CH, Helenowski I, Pelling JC, Bergan RC. Dietary genistein inhibits metastasis of human prostate cancer in mice. Cancer Research 2008;68:2024-2032. [PubMed: 18339885]

Lawson T, Kolar C. Human prostate epithelial cells metabolize chemicals of dietary origin to mutagens. Cancer Letters 2002;175:141-146. [PubMed: 11741741]

Leav I, Ho S, Ofner P, Merk F, Kwan P, Damassa D. Biochemical alterations in sex hormone-induced hyperplasia and dysplasia of the dorsolateral prostates of Noble rats. Journal of National Cancer Institute 1988;80:1045-1053.

Lemmen JG, Arends RJ, van der Saag PT, van der Burg B. In vivo imaging of activated estrogen receptors in utero by estrogens and bisphenol A. Environmental Health Perspectives 2004;112:1544-1549. [PubMed: 15531440]

Lewis DR, Southwick JW, Ouellet-Hellstrom R, Rench J, Calderon R. Drinking water aresenic in Utah: a cohort mortality study. Environmental Health Perspectives 1999;107:359-365. [PubMed: 10210691]

Lo S, King I, Alléra A, Klingmüller D. Effects of various pesticides on human 5alpha-reductase activity in prostate and LNCaP cells. Toxicology In Vitro 2007;21:502-508. [PubMed: 17218080]

Van Maele-Fabry G, Libotte V, Willems J, Lison D. Review and meta-analysis of risk estimates for prostate cancer in pesticide manufacturing workers. Cancer Causes, \& Control 2006;17:353-373. [PubMed: 16596288] 
Mahajan R, Bonner MR, Hoppin JA, Alavanja MC. Phorate exposure and incidence of cancer in the agricultural health study. Environmental Health Perspectives 2006;114:1205-1209. [PubMed: 16882526]

McCormick DL, Johnson WD, Bosland MC, Lubet RA, Steele VE. Chemoprevention of rat prostate carcinogenesis by soy isoflavones and by Bowman-Birk inhibitor. Nutrition and Cancer 2007;57:184-193. [PubMed: 17571952]

Meyer TE, Coker AL, Sanderson M, Symanski E. A case-control study of farming and prostate cancer in African-American and Caucasian men. Occupational and Environmental Medicine 2007;64:155160. [PubMed: 16912087]

Modugno F, Weissfeld JL, Trump DL, Zmuda JM, Shea P, Cauley JA, Ferrell RE. Allelic variants of aromatase and androgen and estrogen receptors: toward a multigenic model of prostate cancer risk. Clinical Cancer Research 2001;7:3092-3096. [PubMed: 11595700]

Moore, RA. Endocrinology of Neoplastic Disease. New York: Oxford University Press; 1947. p. 194

Morrison H, Savitz D, Semenciw R, Hulka B, Mao Y, Morison D, Wigle D. Farming and prostate cancer mortality. American Journal of Epidemiology 1993;137:270-280. [PubMed: 8452135]

Nelson WG, DeWeese TL, DeMarzo AM. The diet, prostate inflammation, and the development of prostate cancer. Cancer Metastasis Reviews 2002;21:3-16. [PubMed: 12400993]

Parent ME, Siemiatycki J. Occupation and prostate cancer. Epidemiology Reviews 2001;23:138-143.

Prince MM, Ruder AM, Hein MJ, Waters MA, Whelan EA, Nilsen N, Ward EM, Schnorr TM, Laber PA, Davis-King KE. Mortality and exposure response among 14458 electrical capacitor manufacturing workers exposed to polychlorinated biphenyls (PCBs). Environmental Health Perspectives 2006;114:1508-1514. [PubMed: 17035134]

Prins GS, Birch L. Neonatal estrogen exposure up-regulates estrogen receptor expression in the developing and adult rat prostate lobes. Endocrinology 1997;138:1801-1809. [PubMed: 9112371]

Prins GS, Korach KS. The role of estrogens and estrogen receptors in normal prostate growth and disease. Steroids 2008;73:233-244. [PubMed: 18093629]

Prins GS, Marmer M, Woodham C, Chang WY, Kuiper G, Gustafsson JA, Birch L. Estrogen receptor$\beta$ messenger ribonucleic acid ontogeny in the prostate of normal and neonatally estrogenized rats. Endocrinology 1998;139:874-883. [PubMed: 9492016]

Prins GS, Birch L, Habermann H, Chang WY, Tebeau C, Putz O, Bieberich C. Influence of neonatal estrogens on rat prostate development. Reproduction, Fertility, and Development 2001;13:241-252.

Prins GS, Birch L, Yang WY, Ho SM. Developmental estrogen exposures predispose to prostate carcinogenesis with aging. Reproductive Toxicology 2007;23:374-382. [PubMed: 17123779]

Prins GS, Tang WY, Belmonte J, Ho SM. Perinatal exposure to oestradiol and bisphenol A alters the prostate epigenome and increases susceptibility to carcinogenesis. Basic Clinical Pharmacology \& Toxicology 2008;102:134-138.

Raghow S, Hooshdraran MZ, Katiyar S, Steiner MS. Toremifene prevents prostate cancer in the transgenic adenocarcinoma of mouse prostate model. Cancer Research 2002;62:1370-1376. [PubMed: 11888907]

Rajfer J, Coffey DS. Sex steroid imprinting of the immature prostate. Investigative Urology 1978;16:186190. [PubMed: 711410]

Ritchie JM, Vial SL, Fuortes LJ, Guo H, Reedy VE, Smith EM. Organochlorines and risk of prostate cancer. Journal of Occupational and Environmental Medicine 2003;45:692-702. [PubMed: 12855910]

Schlumpf M, Jarry H, Wuttke W, Ma R, Lichtensteiger W. Estrogenic activity and estrogen receptor beta binding of the UV filter 3-benzylidene camphor. Comparison with 4-methylbenzylidene camphor. Toxicology 2004a;199:109-120. [PubMed: 15147785]

Schlumpf M, Schmid P, Durrer S, Conscience M, Maerkel K, Henseler M, Gruetter M, Herzog I, Reolon $\mathrm{S}$, Ceccatelli R, et al. Endocrine activity and developmental toxicity of cosmetic UV filters - an update. Toxicology 2004b;205:113-122. [PubMed: 15458796]

Schulze H, Claus S. Histological localization of estrogen receptors in normal and diseased human prostates by immunocytochemistry. Prostate 1990;16:331-343. [PubMed: 1695369]

Smith MR, Malkowicz SB, Chu F, Forrest J, Price D, Sieber P, Barnette KG, Rodriguez D, Steiner MS. Toremifene increases bone mineral density in men receiving androgen deprivation therapy for 
prostate cancer: interim analysis of a multicenter phase 3. Journal of Urology 2008;179:152-155. [PubMed: 18001802]

Song KH, Lee K, Choi HS. Endocrine disruptor bisphenol A induces orphan nuclear receptor Nur77 gene expression and steroidogenesis in mouse testicular Leydig cells. Endocrinology 2002;143:22082215. [PubMed: 12021184]

Steiner MS, Pound CR. Phase IIA clinical trial to test the efficacy and safety of Toremifene in men with high-grade prostatic intraepithelial neoplasia. Clinical Prostate Cancer 2003;2:24-31. [PubMed: 15046680]

Sterling KM, Cutrineo KR. Constitutive and inducible expression of cytochromes P4501A (CYP1A1 and CYP1A2) in normal prostate and prostate cancer cells. Journal of Cell Biology 2004;91:423-429.

Usmani KA, Rose RL, Hodgson E. Inhibition and activation of the human liver microsomal and human cytochrome P450 3A4 metabolism of testosterone by deployment-related chemicals. Drug Metabolism and Disposition 2003;31:384-391. [PubMed: 12642463]

Usmani KA, Cho TM, Rose RL, Hodgson E. Inhibition of the human liver microsomal and human cytochrome P450 1A2 and 3A4 metabolism of estradiol by deployment-related and other chemicals. Drug Metabolism and Disposition 2006;34:1606-1614. [PubMed: 16790556]

Waalkes MP. Cadmium carcinogenesis in review. Journal of Inorganic Biochemistry 2000;79:241-244. [PubMed: 10830873]

Walsh DE, Dockery P, Doolan CM. Estrogen receptor independent rapid non-genomic effects of environmental estrogens on $\left[\mathrm{Ca}^{2+}\right] \mathrm{i}$ in human breast cancer cells. Molecular and Cellular Endocrinology 2005;230:23-30. [PubMed: 15664448]

Watson WH, Yager JD. Arsenic: extension of its endocrine disruption potential to interference with estrogen receptor-mediated signaling. Toxicological Sciences 2007;98:1-2. [PubMed: 17650541]

Wetherill YB, Fisher NL, Staubach A, Danielsen M, de Vere White RW, Knudsen K E. Xenoestrogen action in prostate cancer: pleiotropic effects dependent on androgen receptor status. Cancer Research 2005;65:54-65. [PubMed: 15665279]

Wetherill YB, Hess-Wilson JK, Comstock CE, Shah SA, Buncher CR, Sallans L, Limbach PA, Schwemberger S, Babcock GF, Knudsen KE. Bisphenol A facilitates bypass of androgen ablation therapy in prostate cancer. Molecular Cancer Therapeutics 2006;5:3181-3190. [PubMed: 17172422]

Yonemura CY, Cunha GR, Sugimura Y, Mee SL. Temporal and spatial factors in diethylstilbestrolinduced squamous metaplasia in the developing human prostate. II. Persistent changes after removal of diethylstilbestrol. Acta Anatomica 1995;153:1-11. [PubMed: 8560954]

Yu W, Lee B, Nam S, Ahn B, Hong J, Do J, Kim Y, Lee Y, Yun Y. Reproductive disorders in pubertal and adult phase of the male rats exposed to vinclozolin during puberty. Journal of Veterinary Medical Science 2004;66:847-853. [PubMed: 15297758] 